\title{
Research on Supplier Selection based on AHP
}

\author{
Xiaopeng Zhang \\ Zhengzhou University Administrative Engineering College \\ \{f_author\}422090565@qq.com
}

Keywords: Supplier management; Supplier selection; AHP

Abstract: The economic globalization accelerate the market competition, this circumstances is obliging firms to focus on optimization in all aspects of production and management. Best suppliers is key to enterprise survival or wining in the competition. Supplier's level are different, supplier's selection method becomes the object of the enterprise research. This paper summarizes the selection and evaluation of suppliers at home and abroad, describes the supplier classification, gives the factors of supplier selection, analyzes the principles and methods of supplier selection, outlines the steps of selecting suppliers, studies the selection of suppliers, and finally verifies the feasibility of the case analysis by AHP.

\section{Introduction}

\subsection{Classification and characteristics of suppliers}

In order to make the supply chain to efficiently run, you need to reduce the number of companies supply sources in the supply chain, but this does not mean that advocates for businesses to use a single source of supply, but links between enterprises and suppliers become more proprietary, strategic supplier of enterprise should be few but good and close relationship with manufacturer partners, And secondary supplier comparative more relationships with manufacturers.

Main effects of various changes in the supply chain are strategic partners and other suppliers will be less affected.

Depending on the value-added role and competitiveness of suppliers in the supply chain, they can be broadly grouped into four categories: influential suppliers, strategic suppliers, competitive/technical vendors, and general suppliers, as shown in Figure 1.

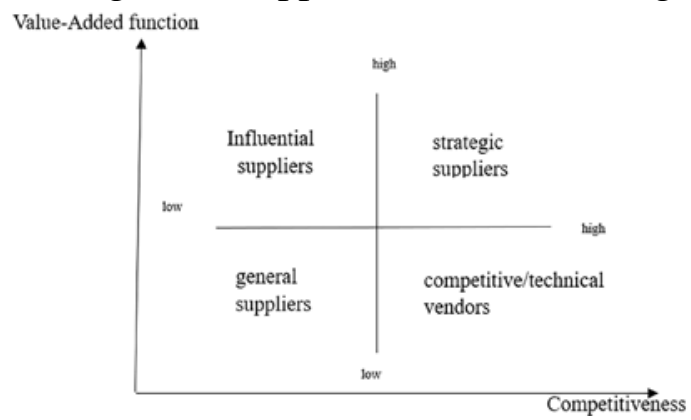

Figure 1 Supplier classification model 
In the actual production and operation process, enterprises should choose different suppliers according to different purposes. For long-term operations, suppliers have a high level of competitiveness and high value-added capacity, enterprises need to choose a strategic supplier; for short or short markets, it is usually sufficient for a business to choose a generic supplier; In the medium term, Companies need to select influential suppliers or competitive/technical suppliers based on their competitiveness and value-added requirements. Various vendors have different characteristics:

1) strategic suppliers. This type of vendor's products and services are very important, high value, and may have significant impact on buyers engaged in production or affect the buyer's ability to meet customer needs. These suppliers should establish long-term relations of cooperation.

2) Influential supplier. Usually the supplier already has the quality and technical standards, rather than form alliances or strategic partners of little value, so you only have to purchase or sign a long-term agreement in accordance with the requirements.

3) Competition/technical suppliers. This type of vendors have proprietary technology, it is difficult to be replaced, so purchasing these products that consume a lot of time and effort. For this type of supplier, the purchaser shall as far as possible a reduction in Procurement Division needed, make the transaction standardization, simplification in order to reduce costs.

4) General supplier. These suppliers are no high added-no more competitive, and numerous, usually in accordance with the standard of quality of its products and technology, supplier switching costs are low, procurement should be focusing on price, according to the market demand determine the most suitable product. For the supplier, can put pressure on it or sign a short-term deal to reduce costs. There is no need to establish partnerships with such suppliers.

\subsection{Conditions for supplier selection}

Typically, enterprises in the supply chain in the supplier selection through a variety of indicators to evaluate suppliers, Enterprise assessment of suppliers not stop with decision-making, Enterprise after the established supply relationships still need to carry out a follow-up evaluation of vendors, according to different criteria to analyze whether suppliers needs to be replaced.

A good supplier is usually a partner to be courted by many enterprises, the most important condition of being a good supplier is to have excellent products, and a good product usually shows:

1) Quality. for a product, the importance of quality is self-evident, it determines the position of suppliers in the heart of the enterprise, excellent quality easier to obtain the favor of enterprises.

2) Price. in the case of quality is guaranteed, price is an important enterprise vendor selection criteria.

3) High scientific and technological content of products, advanced technology and good development prospects.

4) Abundant supply, stable supply. Enterprises with such products are generally powerful large enterprises.

Enterprises will be competitive in selecting suppliers, for the enterprise, a good supplier usually should have at least the following conditions:

1) The technical level. Technical level refers to the ability of suppliers to meet the requirements of the enterprise specifications. Ability of supplier's product development and improvement; Can the supplier help to improve the product? These are not important to the enterprise, a high tech level supplier can help the enterprise to develop better.

2) Product quality. A reliable product is an important index for the enterprise to evaluate the supplier. The products provided by the supplier must be able to meet the needs of the enterprise continuously and stably, which requires the supplier to have a perfect quality control system. 
Inspection of the quality of the products provided by the supplier should not only stop the quality inspection in the factory, but also test its actual use.

3) Supply capacity. Supply capacity is the production capacity of suppliers, enterprises need to investigate the size of suppliers and development potential. To ensure that enterprises continue to grow and develop at the same time, suppliers can keep up with the enterprise development, and continuously meet the production needs of enterprises, to ensure that enterprises will not be due to supply shortage and stop production.

4) Price. Vendors need to provide the most competitive price, that does not mean the lowest price. This price should be considered enterprise require suppliers to provide time, determine the quantity, quality and service. Suppliers should also have the ability to provide product cost improvements to the purchaser.

5) Geographic location. Inventory products tend to be decided by the vendor's location, high demand and high price of the product, and proximity of enterprise supplier management. Companies always want their suppliers to distance their closer, some will require suppliers to establishment of warehouses in enterprises are located, short distance transport time is shorter, means that at the peak of production enterprises can quickly get raw materials, reduced production of raw material shortage pressure.

6) Reliability. Reliability or suppliers of credit, businesses in supplier selection, good credit, good financial situation of enterprises in General will be priorities. Meanwhile, both supply and demand should be continuing good credit, will be maintained.

7) After-sales service. Maintain strategic partnership needs of both supply and demand and good after-sales service, as well as exchanges in the aspects of both supply and demand on product quality conditions.

8) Lead time. Under the condition of traditional condition or supply chain management, the supplier should have a reasonable supply lead time in order to deal with the possibility of emergency, which can greatly shorten the delivery lead time under the condition of supply chain management.

9) Delivery accuracy. If a business is establishing strategic partnerships with suppliers, then communication between enterprises and suppliers more time, vendor product return ratio can greatly reduce, but also improves the accuracy of delivery.

10) Quick response capability. Due to the addition of computer technology, the responsiveness of suppliers to customer demand in supply chain is greatly improved compared with traditional suppliers, and the ability of suppliers to respond to customers ' desires is greatly improved, so in the supply chain, responsiveness is an important factor to evaluate suppliers.

In addition to the above listed requirements, suppliers of corporate culture and strategic planning and vendor, such as the external environment is also an important index to measure supplier and, therefore, to vendor selection to some scientific and rigorous approach.

\subsection{Research on domestic supplier selection mechanism}

Since the idea of supply chain management came into the country in the 90 's, both academic and business circles have paid much attention to it. Chinese scholars have also begun to study the selection and evaluation of suppliers, along with the development of the economy, research is also more and more in-depth.

Mashua and Yong in supply chain management, a comprehensive index system for supplier selection in the Supply chain environment includes: Enterprise environment, enterprise performance, quality system, business structure and production capacity (Yong,Lin. Shihua, Ma, 2000). Its comprehensive indicator system is shown in table 1: 
Table 1 Integrated Indicators system

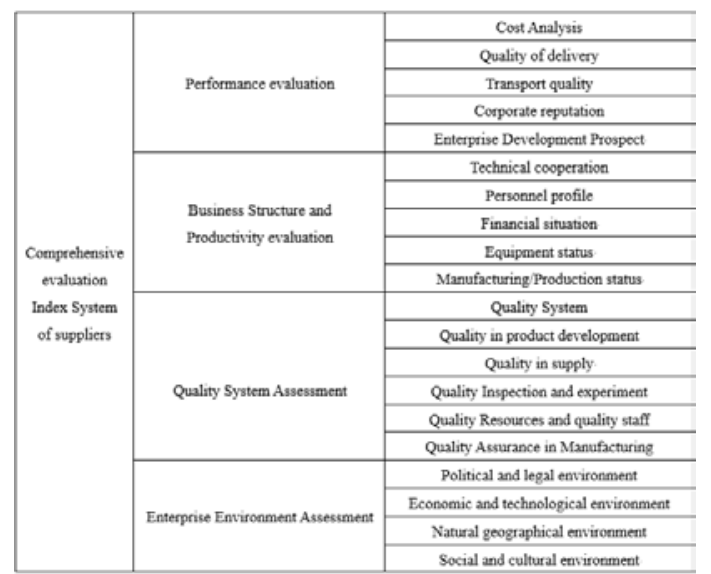

In 1998, ShiYong, Chen in the Citroen automobile company survey and auto parts suppliers on the basis of the proposed assessment should compare suppliers to suppliers in terms of quality, bulk flexibility, quality, delivery, delivery time and price balance, diversity, and other aspects of content, not just under the price came to the conclusion(Shuyong, Kan,Rongqiu, Chen, 1998.).

In 2000, Zhu Daoli, scholars such as ERP software vendor to conduct in-depth research, supplier evaluation index for the industry are presented, including suppliers of technical characteristics, features, cost, and user service indicator. Blue people think: time (t), quality (Q), cost (c), the service (s) is an important cause of success(Daoli, Zhu. Hong, Lin. Xianwen, Zeng,2000.).

In 2002, Ma Lijuan presented 9 evaluation indicators for supplier selection: Product price, product quality, economic benefit, technical level, economic benefit, supply capacity, geographical location, after-sale service, delivery status and market impact degree(Linjuan, Ma, 2002).

In 2009, Wang Chuanming put forward through the establishment of comprehensive evaluation system of dynamic management system for suppliers and the establishment of, and then select Vendor approaches through qualitative or quantitative methods(Chuanming, Wang, 2009).

In 2013, Wang Aijun and Yang Weidong put forward a new evaluation index of supplier selection through the integration of predecessors ' research: product factors, enterprise factors and cooperation compatibility. The performance level of the supplier is divided into three dimensions, the three-dimensional cube is constructed, the actual performance points are obtained by calculating the performance points of each dimension, and the suppliers are selected by comparison with the optimal performance points(Aijun, Wang.Weidong, Yang, 2013).

\section{Methods}

\subsection{Supplier selection mechanism}

\subsubsection{Principles for selection of suppliers}

The successful experience has shown that many enterprises, and develop new suppliers of basic points: clear objectives, carry out thorough investigation and study and understand the overall situation, balancing, selection. Enterprises in the supply chain when selecting a new supplier usually follows the following principles:

1) Target positioning principle. This principle requires that new supplier evaluations should focus on extensive and in-depth inspection of suppliers, and should ensure that suppliers are selected according to the characteristics, quantity and quality of purchased goods, so that they can build quality assured procurement channels, reduce procurement risks, and help their products enter 
the target market. So that customers have confidence in the products of the enterprise.

2) Principle of complementary advantages. In the development of new suppliers should be aware of their business direction and technical capacity to meet the requirements of the enterprise, the supplier in some areas should be more advantageous than the purchaser, so that in the future with the procurement side to achieve complementary purposes. In the establishment of key, important components, especially pay attention to the supplier's production capacity, long-term supply capacity, technical level and advantages. Only the business philosophy and technical level to meet the requirements of the enterprise suppliers can become the enterprise production and management and future development of a faithful partner.

3) Select principles. Under the same pricing and delivery commitments, no doubt you want to choose a good corporate image, can give the famous supplier of high quality and their supply. Reputable companies make promises higher reliability.

4) Common development principles. In today's environment, the market competition is more and more fierce, enterprises in the actual operation will inevitably be affected by suppliers. If the supplier can fully cooperate with the development of enterprises, and the common interests of enterprises in the supply chain in their own interests first, then both the supply and demand can stand in the market more stable, can respond to the changes in the market faster, but also more conducive to access to greater market share.

\subsubsection{Supplier selection step}

Enterprises in the supply chain are generally divided into five steps when making supplier selection:

1) Identify requirements. Enterprises in general in two cases will have the choice of the supplier's needs: first, enterprises need to produce new products to develop new markets, but the original suppliers can not meet the needs of new product production raw materials; second, the original supplier of the enterprise is not to provide raw materials for enterprises.

2) Identify alternative suppliers. When the enterprise has supplier needs, it will first identify potential suppliers, or within a certain range of public bidding, query supplier information files or participate in trade fairs to determine alternative suppliers.

3) Establish a performance evaluation system. Enterprises need to establish scientific and effective supplier performance evaluation systems as a basis for supplier selection and evaluation.

4) Supplier performance evaluation. After the collection of sufficient information on alternative suppliers and the establishment of a sound performance evaluation system, the information entry performance evaluation system needs to be evaluated by each supplier to determine the actual performance level of each supplier.

5) Identify suppliers. The final step in selecting suppliers, that is, to fully evaluate and select alternative suppliers best meet the requirements of the supplier.

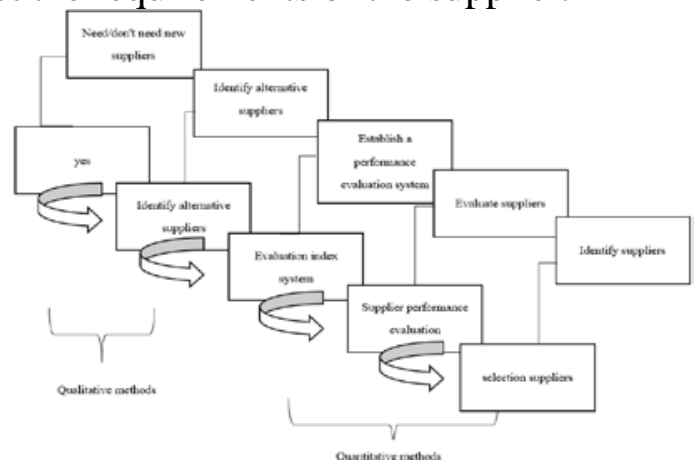

Figure 2-step model for supplier selection 


\subsection{Supplier selection in supply chain based on AHP evaluation model}

\subsubsection{Basic principle of analytic hierarchy process}

Analytic hierarchy process as a combination of qualitative and quantitative methods, complex problems can be reduced to a large number of ordered levels in non-quantitative quantitative very effective. Sorted by calculation, you can get the effects of factor intensity and the final results, provide references to policy makers.

\subsubsection{Implementation steps of analytic hierarchy process}

1) Analysis of the relationship between the evaluation system of the basic elements to establish the hierarchical structure of the system, as shown in Figure 3.

2) Elements on the same level on the previous level in the importance of standards for comparable constitutes a comparison matrix as shown in table 2.

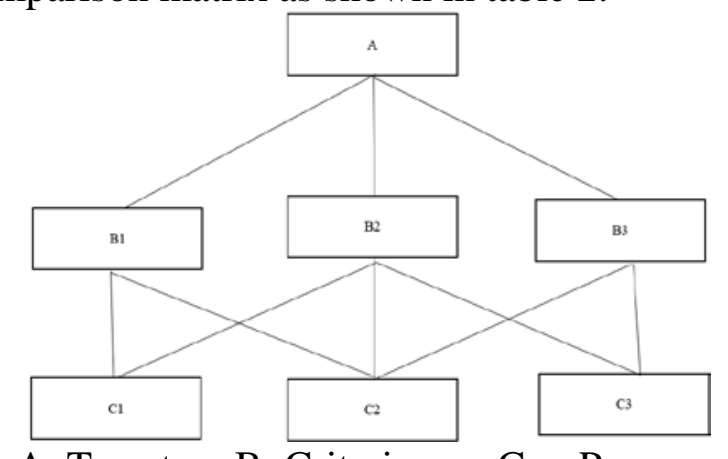
A: Target
B: Criterion
C: Program

Figure 3 model of hierarchical structure

Table 2 basic form of judgment matrix

\begin{tabular}{|l|l|l|l|}
\hline $\mathrm{A}$ & $\mathrm{B} 1$ & $\mathrm{~B} 2$ & $\mathrm{~B}$ \\
\hline $\mathrm{B} 1$ & $a_{11}$ & $a_{12}$ & $a_{13}$ \\
\hline $\mathrm{B} 2$ & $a_{21}$ & $a_{22}$ & $a_{23}$ \\
\hline $\mathrm{B} 3$ & $a_{31}$ & $a_{32}$ & $a_{33}$ \\
\hline
\end{tabular}

It indicates the importance scale of $\mathrm{a}_{i j}$ element I compared with factor $\mathrm{j}$, and the scale definition is shown in table 3 .

Table 3 scales of judgement matrix definition

\begin{tabular}{|l|l|}
\hline Scale & Meanino(Comnared to the two elements) \\
\hline 1 & Have the same importance \\
3 & The former is slightly more important than the latter. \\
5 & The former than the latter obviously important \\
7 & The former than the latter strongly important \\
9 & The former than the latter is extremely important \\
\hline 2.46 .8 & Intermediate values of the adjacent judgments above \\
\hline Countdown & The importance of the latter than the former scales \\
\hline
\end{tabular}

3) To find the normalized relative importance vector $w^{\circ}=w_{i}^{o}$ of each element relative to the upper level (criterion layer), namely:

$$
w^{o}=\left(\prod_{j=1}^{n} a_{i j}\right)^{\frac{1}{n}} \quad w_{i}^{o}=\frac{w_{i}}{\sum_{i} w_{i}}
$$

After obtaining the important degree vector $\mathrm{W}$ or $w^{0}$, we can do the calculation of $\lambda_{\max }$ and the 
consistency index C.I.

$$
\begin{gathered}
C . I .=\frac{\lambda_{\max }-n}{n-1} \\
\lambda_{\max } \approx \frac{1}{n} \sum_{i=1}^{n} \frac{(A W)_{i}}{w_{i}}=\frac{1}{n} \sum_{i=1}^{n} \frac{\sum_{j=1}^{n} a_{i j} w_{j}}{w_{i}}
\end{gathered}
$$

$(A W)_{i}$ represents the i-th component of a vector $A W$.

When C.I.of the small note matrix consistency value is better, but worse, when the C.I. $=0$ indicates that the judgment matrix has complete consistency. In order to test whether the judgment matrix is consistent, you need to judge C.I. and R.I. the C.R.mean random consistency index. R.I.that can be obtained through table 4 queries.

Table 4 average random consistency index

\begin{tabular}{|c|c|c|c|c|c|c|c|}
\hline N & 1 & 2 & 3 & 4 & 5 & 6 & 7 \\
\hline R.I. & 0 & 0 & 0.52 & 0.89 & 1.12 & 1.26 & 1.36 \\
\hline N & 8 & 9 & 10 & 11 & 12 & 13 & 14 \\
\hline R.I. & 1.41 & 1.46 & 1.49 & 1.52 & 1.54 & 1.56 & 1.58 \\
\hline
\end{tabular}

When $C . R .=\frac{C . I .}{R . I .}<0.1$, the satisfaction degree of the judgment matrix is considered to be consistent.

4) Each layer elements for system purposes (goals) synthesis of (gross) weight and sort option. Total importance calculation tables table 5.

Table 5 total progress table

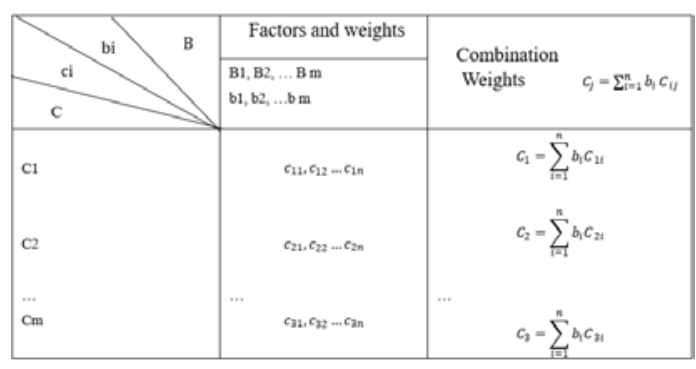

\section{Material and results}

\subsection{Enterprise profile}

M Enterprise is a large state holding products manufacturing enterprises, its flagship product has accounted for $70 \%$ of the market share.

Enterprises have a strong research and development capabilities and excellent and stable management staff, the enterprise to "provide users with value-added products and services" as the goal, in the national scope to establish a large number of special repair stations and maintenance services center, so that the domestic repair stations received service information can be timely feedback to the enterprise.

With the continuous development of enterprises, $M$ enterprise suppliers in the number of increasing, the size of nearly thousands of suppliers throughout the country, some parts also need to be purchased abroad. This article assumes that $\mathrm{m}$ companies are developing new products that require a newer part and that previous suppliers are not able to provide this new part. W Enterprises need to incorporate new suppliers into the supply chain for the production of such parts. $\mathrm{M}$ Company will select suppliers from four aspects, such as quality, cost, delivery and service. 


\subsection{Using AHP to select suppliers}

First step, establish a hierarchical structure.

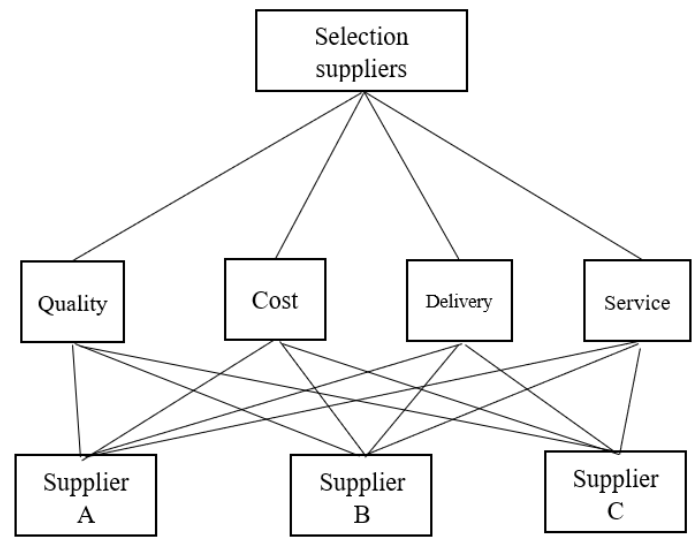

Figure 4 hierarchical structure

The second step is to form a group of experts to decide the final score for each indicator. Lists the judgment matrix, carries on the level order and the consistency examination.

Table 6A-B Judgement matrix

\begin{tabular}{|l|l|l|l|l|l|l|}
\hline $\begin{array}{l}\text { Supplice } \\
\text { Advantage }\end{array}$ & Quality & Cost & Delivery & Service & $\boldsymbol{W}_{\boldsymbol{i}}$ & $\lambda_{\text {mat }}$ \\
\hline Quality & 1 & 2 & 1 & 3 & 1.565 & 4.023 \\
\hline Cost & $1 / 2$ & 1 & $1 / 2$ & 3 & 0.931 & 4.162 \\
\hline Delivery & 1 & 2 & 1 & 2 & 1.414 & 4.110 \\
\hline Senvice & $1 / 3$ & $1 / 3$ & $1 / 2$ & 1 & 0.485 & 4.173 \\
\hline
\end{tabular}

By using the method of square root, we can calculate the importance weight and the consistency test parameters of each factor to the target layer.

Table 7 Matrix Weights

$$
\lambda_{\max }=4.1 \quad \text { C.I. }=0.039 \quad \text { C.R. }=0.04<0.1
$$

\begin{tabular}{|c|c|c|c|c|}
\hline Inadictares & Q emilty & Cost & Delinery & Servises \\
\hline Wéght & 0.356 & \begin{tabular}{|l|l|l|} 
\\
\end{tabular} & 0.322 & $0.110^{\prime}$ \\
\hline
\end{tabular}

The judgment matrix is satisfactory by C.R. $<0.1$ Calculation of B-C matrix continues to score by the Expert group.

Table 8 Quality-Supplier judgment matrix

\begin{tabular}{|l|cccc|c|c|}
\hline Quality & Supplier A & Supplier & B & Supplier C & $\boldsymbol{W}_{\boldsymbol{i}}$ & $\lambda_{m i}$ \\
\hline Supplier A & 1 & $1 / 3$ & $1 / 5$ & 0.405 & 3.041 \\
\hline Supplier B & 3 & 1 & $1 / 3$ & 1.000 & 3.037 \\
\hline Supplier C & 5 & 3 & 1 & 2.466 & 3.038 \\
\hline
\end{tabular}

Table 9 supplier weight based on quality indicators

$\lambda_{\max }=3.039$ C.I. $=0.02$

\begin{tabular}{|l|l|l|l|}
\hline & Supplier A & Supplier B & Supplier C \\
\hline Weight & 0.105 & 0.258 & 0.637 \\
\hline
\end{tabular}

C.R. $=0.038<0.1$

Table 10 Cost-Supplier judgment matrix

\begin{tabular}{|l|cccc|c|c|}
\hline Cost & Supplier A & \multicolumn{2}{|l|}{ Supplier B } & Supplier C & $\boldsymbol{W}_{\boldsymbol{i}}$ & $\lambda_{m i}$ \\
\hline Supplier A & 1 & 2 & 5 & 2.154 & 3.003 \\
\hline Supplier B & $1 / 2$ & 1 & 3 & 1.145 & 3.002 \\
\hline Supplier C & $1 / 5$ & $1 / 3$ & 1 & 0.405 & 3.006 \\
\hline
\end{tabular}

Table 11 supplier weight based on cost indicators

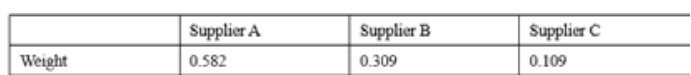




$$
\lambda_{\max }=3.0 \text { C.I. }=0.002 \quad \text { C.R. }=0.004<0.1
$$

Table 12 Delivery-Supplier judgment matrix

\begin{tabular}{|c|c|c|c|c|c|}
\hline Delivery & Supplier A & Supplier B & Supplier C & $w_{i}$ & $\lambda_{m i}$ \\
\hline Supplier A & 1 & 4 & 3 & 2.289 & 3.009 \\
\hline Supplier B & $1 / 4$ & 1 & 1 & 0.630 & 3.008 \\
\hline Supplier C & $1 / 3$ & 1 & 1 & 0.693 & 3.010 \\
\hline
\end{tabular}

Table 13 supplier weight based on delivery indicators

$$
\lambda_{\max }=3.00 \text { C.I. }=0.05
$$

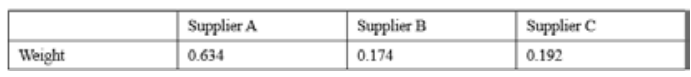

$$
\text { C.R. }=0.096<0.1
$$

Table 14 Service-Supplier judgment matrix

\begin{tabular}{|l|ccc|c|c|}
\hline Service & Supplier A & Supplier B & Supplier C & $\boldsymbol{W}_{\boldsymbol{i}}$ & $\lambda_{m i}$ \\
\hline Supplier A & 1 & $1 / 2$ & 2 & 1.000 & 3.000 \\
\hline Supplier B & 2 & 1 & 4 & 2.000 & 3.000 \\
\hline Supplier C & $1 / 2$ & $1 / 4$ & 1 & 0.500 & 3.000 \\
\hline
\end{tabular}

Table 15 supplier weight based on Service indicators

$\lambda_{\max }=3.000 \quad$ C.I. $=0 \quad$ C.R. $=0<0.1$

\begin{tabular}{|l|l|l|l|}
\hline & Supplier A & Supplier B & Supplier C \\
\hline Weight & 0.286 & 0.571 & 0.143 \\
\hline
\end{tabular}

\begin{tabular}{|c|c|c|c|c|c|}
\hline & Quality & Cost & Delivery & Service & $c_{j}=\sum_{b_{1}}^{n} c_{i j}$ \\
\hline c & 0.356 & 0.212 & 0.322 & 0.110 & \\
\hline Supplier A & 0.105 & 0.582 & 0.634 & 0.286 & 0.396 \\
\hline Supplier B & 0.258 & 0.309 & 0.174 & 0.571 & 0.277 \\
\hline Supplier C & 0.637 & 0.109 & 0.192 & 0.143 & 0.327 \\
\hline
\end{tabular}

The third step is to carry out the level of total ranking and consistency test.

Table 16 Total ordering and consistency check

Results show that the 3 suppliers in the appropriate order for $A>C>B$, so $M$ Enterprises should choose supplier A to supply the raw materials for their new products.

\section{Conclusion}

This paper summarizes the domestic predecessors of the Supplier Evaluation Index System research, and then analyzes the supplier classification and characteristics, and the supplier to select the need to have some conditions and in the selection of suppliers is to follow the principle, listed some selection of suppliers is a common step. Finally, the application of analytic hierarchy process to enumerate the examples to verify, but in the actual production and management activities in the selection of suppliers involved in a very complex, enterprises want to get the ideal supplier needs to do more work, but the enterprise may not have enough time to consider all aspects, This requires more optimization on the method chosen by the supplier, saving the time required to select the supplier.

\section{References}

[1] Aijun, Wang.Weidong, Yang, 2013. Research on Supplier Selection Evaluation Based on 3D Cube. China Journal of Commerce,32: 167-170.

[2] Badri MA. A Combined AHP-GP Model for Quality Control Systems. International Journal Production Economies,2001,72 (1): 27-40.

[3] Chuanming, Wang, 2009. Discussion on supplier management. Modern Economic Information,17: 146 
[4] Daoli, Zhu. Hong, Lin. Xianwen, Zeng,2000. Supplier Selection Decision--Integrated Management Software ERP System Supplier Selection. Logistics Technology,2: 25-27.

[5] Hongyan, Hen,Junyong, Zhu,2005. Overview of supplier selection methods. Hebei Journal of Industrial Science and Technology,5: 308-311.

[6] Lei, Liu. Xiaowo, Tang.Yixiang, Ding,2005. Supplier Flexibility Evaluation under Supply Chain Management Mode. Commercial Research,15: 6-8.

[7] Linjuan, Ma, 2002. Probe into the Problem of Supplier Selection Based on Supply Chain Management. Industrial Engineering and Management,6: 23-25.

[8] Satty TL, Alexander JM. Thinking With Models: Mathematical Models in the Physical, Biological and Social Sciences. Oxford: Pergamon Press,1981.

[9] Shiqiang, Tang.Xinde, Chen, 2004. Empirical Research on Supply Chain Management Evaluation Method. Shanghai Management Science,6: 39-41.

[10] Shuyong, Kan,Rongqiu, Chen, 1998. On the relationship between manufacturers and suppliers in the JIT environment. Journal of Industrial Engineering and Engineering Management, 12 (3): 46-52.

[11] Yong,Lin. Shihua, Ma, 2000. Research on Comprehensive Evaluation Choice of Suppliers in Supply Chain Management Environment. Logistics Technology,5 : 30-32. 